\title{
Design and Implementation of Surface Water Pollution Monitoring Information System in Xinxiang City
}

\author{
Zheng Hongyan \\ Center for Earth Observation and Digital Earth, \\ Chinese Academy of Sciences \\ Graduate University of Chinese Academy of Sciences \\ Beijing, China \\ zhenghongyan5540@163.com \\ Wang Liming \\ Center for Earth Observation and Digital Earth, \\ Chinese Academy of Sciences \\ Graduate University of Chinese Academy of Sciences \\ Beijing, China \\ lmwang@ceode.ac.cn
}

\begin{abstract}
Information management of surface water pollution is one of the most important aspects of environmental management, which can effectively manage and visualize water pollution monitoring information. Water quality model is key technology of surface water pollution monitoring, which concerns about monitoring precision of pollutant concentration. Taking the design and realization of the surface water pollution monitoring information system in Xinxiang city, Henan province as an example, adopting component GIS technology and taking advantage of the perfect combination of Map Objects and Visual Basic 6.0, the paper discusses how to perform the secondary development by integrating water quality model and GIS. The system not only realized visual expression of surface water pollution situation and prediction of pollutant concentration, but also provided scientific methods and modern means for information management of water pollution in Xinxiang city.
\end{abstract}

Keywords-GIS, MapObjects, Water quality model, Water quality pollution

\section{INTRODUCTION}

There has been pressure of water environment from many aspects in China for a long time, including water pollution, water shortages, flood disaster, and so on. Water pollution increased water shortages. Ecological environment deterioration is one of the important causes of flood disaster. Within quite a long time in the future, water pollution will remain an extrusive problem of water environment in China. Analyzing current water environment situation correctly and doing prevention work of water pollution well have important practical significance in improving water quality [1].

With the continuous development of information science, geographic information system (GIS) technique has come into wide use nowadays. The application of GIS in water environment mainly lies in following aspects: (1) region water environment management; (2) water

\author{
Lin Qizhong \\ Center for Earth Observation and Digital Earth, \\ Chinese Academy of Sciences \\ Graduate University of Chinese Academy of Sciences \\ Beijing, China \\ qzlin@ceode.ac.cn \\ Bai Xuehong \\ Center for Earth Observation and Digital Earth, \\ Chinese Academy of Sciences \\ Graduate University of Chinese Academy of Sciences \\ Beijing, China \\ xhbai@ceode.ac.cn
}

environment evaluation and planning; (3) water environment simulation; (4) nonpoint source pollution control; (5) environmental protection emergency responses, etc [2]. Taking advantage of GIS technique which can process spatial data and visualize information, this paper designs and develops surface water pollution monitoring information system to better perform effective prediction and control on surface water pollution in Xinxiang city, which not only provide basis for relevant department and staff to make spatial-temporal analysis of water pollution information, but also provide scientific method and decision for formation management of surface water pollution in Xinxiang city.

\section{WATER QUALITY MODEL}

Water quality mathematical model (short for water quality model) is mathematical description and simulation of water containing materials' (including chemicals, radioactive materials and organisms) physical, chemical and biological variety of responses and complex migration and transformation process for the role of hydrodynamics and biochemistry [3]. Being useful tools for water resources planning and management, evaluation of water environment impact, water quality prediction, pollution control and use of water resources, water quality model plays an extremely important role in water environment and is applied more and more widely. Surface water environment impact prediction includes impact prediction of river, estuaries, big and small lake and gulf water environment, its prediction model has zero-dimension, one-dimension and two-dimensional water quality model [4].

In this paper, the system adopts zero-dimensional water quality model. Regarding a river or river section as a completely mixed reactor, calculate river outflow pollutant concentration according to upper reach river inflow, upper reach pollutant concentration, waste water emissions from draining exit and effluent concentration of pollutant. Equation [5] of point source, river water and sewage 
dilution is shown in the following formula:

$$
C=\frac{Q_{P} C_{P}+Q_{E} C_{E}}{Q_{P}+Q_{E}}
$$

Where: $\mathrm{C}$ represents pollutant concentration of lower reach (mg/L); QP upper reach river inflow (m3/s); CP upper reach water quality concentration $(\mathrm{mg} / \mathrm{L})$; $\mathrm{QE}$ waste water emissions from draining exit (m3/s); CE effluent concentration of pollutant from draining exit.

Integration of water quality model and GIS is reflected in water quality prediction module as introduced in later section.

\section{DESIGN OF SYSTEM ARCHITECTURE}

Using $\mathrm{C} / \mathrm{S}$ mode, this system consists of low-level databases, functional module and graphical user interface. According to structured analysis and design of system, this system contains four main modules: data input/output module, map layer management module, data search module and water quality prediction module. The system architecture is show in Figure.1.

\section{A. General functions of GIS system}

There are some general functions in data input/output module and map layer management module. Map browse, map layer and legend operation, map input and output, and so on are realized.

\section{B. Data search function}

Data search module provides attribute query, spatial query and water quality query. In this module attribute of each layer and each feature entity can be queried, for example name of feature, area of region, length of river, and so on. Spatial query window provides some simple operators. Using these operators, target identifier can be obtained, the entity feature which meet the condition will be highlighted in view window by searching corresponding spatial object in the figure data file according to the target identifier. Water quality query function provides different months of pollutant concentration and monitoring standard in each river section. The data can be added, saved and modified too. Pollutant concentration can be predicted by using its variation trend figure.

\section{Water quality prediction module}

This module presents the integration of GIS and water quality model. It is the out standing feature of this system. It is actually a prediction module by which pollutant concentration in a downstream river section can be predicted. In the concentration calculation window, calculate downstream pollution concentration by inputting some parameters such as upstream river inlet flow, estuary section pollutant concentration, outfall waste water emission, pollutant concentration emission, etc.

\section{DATABASE TECHNIQUES OF SYSTEM}

The management style of spatial data in GIS includes mixed management of file-relation database, management of relational database, management of object-relation database, management of object database, and so on [6-7]. According to system requirements and result of analyzing the characteristic of attribute data and spatial data, this system adopts mixed management of file-relation database.

1) Establishment of spatial database. Spatial feature data consists of fundamental geographic information and related information of surface water environment. In this system, the former includes Xinxiang city's boundary, city's administrative districts, irrigation channels, roads, settlement, etc. The latter includes rivers, hydrometric station, water quality monitoring section, etc. Generate shapefiles by using ArcGIS software and layered management method to vectorize spatial data. As there is a small amount of spatial data in research area, spatial data is saved as file.

2) Establishment of attribute database. Compared to spatial data's structure, attribute data's structure is much simpler. It is usually stored and managed by using relational database. There are several different formats to store attribute data in research area, mainly including Excel *.XLS format, Access *.mdb format, and dBASE *.dbf format. There are also non-electronic format files, so they should be converted to electronic ones.

\section{IMPLEMENTATION OF SYSTEM}

\section{A. Development method of system}

This system is referred to process and analyze spatial data and attributes data of surface water pollution. It is an application-oriented GIS [8]. There are mainly three development ways of application-oriented GIS: independent development, pure secondary development and integrated secondary development. Integration of GIS software and visual programming language becomes the mainstream of application-oriented GIS development means [9]. At present, the integrated secondary development has two ways to realize: OLE/DDE technology and ComGIS technology[10]. According to the needs of study and feature of research area, this paper adopts ComGIS technology to perform system development.

\section{B. Development tool of system}

1) The choice of GIS development platform. Taking existing condition and practicability into consideration, MapObjects technology is mature, its development expansion is lower, and its function can meet study requirement, so MapObjects ComGIS technology is chose for this system.

2) The choice of programming development language. This system takes Visual Basice6.0 as integrated development tool. Because it is easy to seamlessly integrate Visual Basice6.0 and MapObjects, and it can multi-level access data layer, presentation layer and interface layer of components. At the same time, it is convenient to develop targeted auxiliary function for it supports to insert other analysis controls of professional model into system.

3) The choice of database. Access database supports 
seven objects including table, query, form, report, and so on to establish database. Multiple guides, builders and templates can standardize operations such as data storage, data query, interface design, report generation, and so on.

\section{SUMMARIES}

This paper successfully develops surface water pollution monitoring information system in Xinxiang city by using VB and MapObjects control technology. On the one hand, this system integrates water quality model and GIS into together; on the other hand, it realizes information visualization of combining spatial information and attribute information. It makes certain progress in the aspect of surface water monitoring based on GIS technology. The value of this system is that it not only provides rich surface water monitoring information for relevant departments in Xinxiang city, but also provides vivid and direct understanding of water quality conditions to make management decision for completing the water pollution prevention and control.

\section{ACKNOWLEDGMCNTS}

This work is supported by major project of the Digital Earth Science Platform, NO.DESP01-04-10 and the National Natural Science Foundation for Young Scientists of China, NO.41001266.

\section{REFERENCES}

[1] GENG Qing-zhai. Integrated Research of Water Quality Model Based on GIS and Development of Water Environment Information Management System. Hohai University [D], 2004, PP: 1-75

[2] CHEN Jin. A System Designation for Land Use Planning Environmental Impact Assessment Based on GIS. Central China Normal University [D], 2006, PP: 1-20

[3] FU Guo-wei; CHENG Sheng-tong. Water Pollution Control Planning. Beijing: Tsinghua University Press [M], 1985, PP: 70-72

[4] TIAN Zi-gui; GU Ling. Environmental Impact Assessment. Beijing: Chemical Industry Press [M]. 2004, PP: 66-95

[5] JIN La-hua; FENG Jun. Water Environment Numerical Simulation and Visualization Technology. Beijing: Chemical Industry Press [M]. 2004, PP: 65-66

[6] GONG Jian-ya. Concepts and Development of Spatial Database Management System. Science of Surveying and Mapping [J], 2001, PP: 4-8

[7] DONG Kai; FANG Yu. Concept of Spatial Database Model and Its Architecture Research. Geomatics World [J], 2004, PP: 8-16

[8] HE Zhen-ming; HU Jian-wu. The Choice of Applied GIS development means. Science \& Technology Progress and Policy [J]. 2003, PP: 208-209

[9] WANG Tao; CHEN Wei. Research of GIS Secondary Development Based on MapObjects. Science \& Technology Information [J]. 2009, PP: 571-572

[10] YANG Yong-ju; QIAO Xu-ning; QIANG Xu-ming. Design of County Economy Information System Based on MapObjects. Geospatial Information [J]. 2010, PP: 70-72

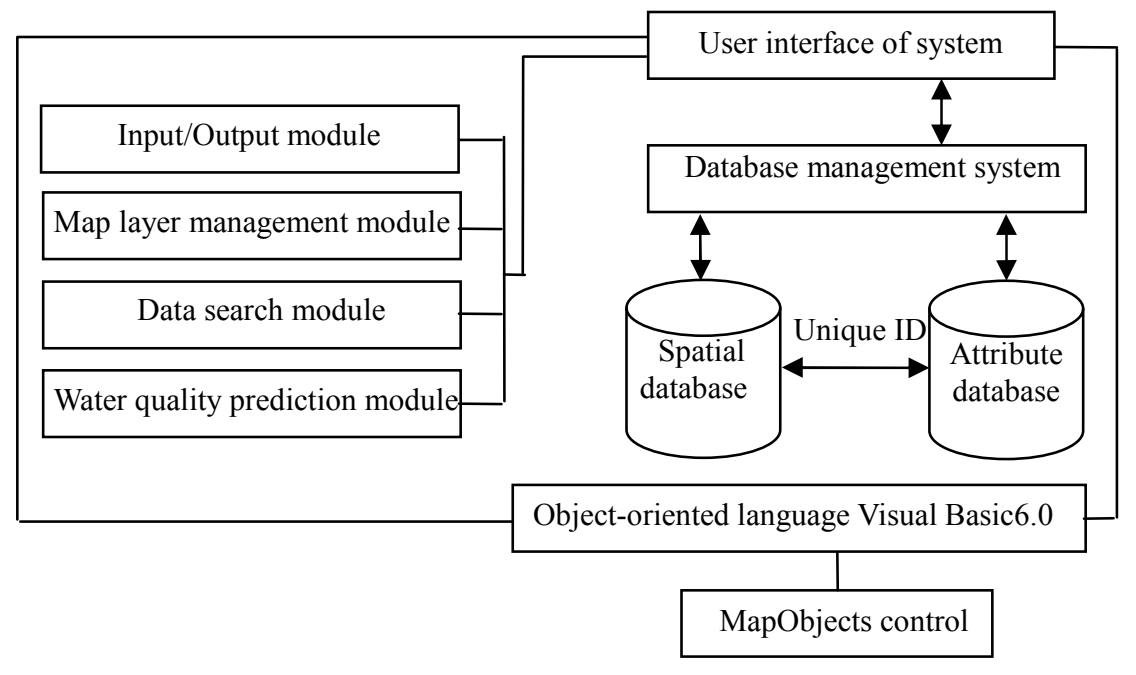

Figure 1. The organization structure of system 